\title{
Escola Primária em Mato Grosso: aspectos de uma cultura escolar em construção $(1910-1915)^{1}$
}

\section{Primary School in Mato Grosso: aspects of an educational culture in construction (1910-1915)}

\author{
Cancionila Janzkovski Cardoso ${ }^{2}$ \\ Lázara Nanci de Barros Amâncio ${ }^{3}$
}

\begin{abstract}
RESUMO
Apresentamos dados de uma pesquisa que contribui para a reconstrução da memória da cultura escolar primária, na perspectiva da História Cultural e da Cultura Escolar. Recorremos aos Relatórios da Diretoria da Instrução Pública, elaborados pelo Major José Estevão Corrêa nos cinco primeiros anos que se seguem à reforma da instrução pública realizada em 1910. Resultados indicam as relações de força entre educadores paulistas e autoridades educacionais de Mato Grosso, na instauração de um novo modelo de escola, tendo como decorrência a construção de uma cultura escolar diferenciada da que vigorou até a primeira década do século XX.
\end{abstract}

Palavras-chave: memória da escola primária; cultura escolar; grupos escolares.

1 Pesquisa desenvolvida no Grupo de Pesquisa ALFALE, coordenada pela professora Lázara Nanci de Barros Amâncio e financiada pela Fundação de Amparo à Pesquisa de Mato Grosso (FAPEMAT), a quem agradecemos.

2 Professora Associada III da Universidade Federal de Mato Grosso (UFMT), campus de Rondonópolis. Coordenadora do Programa de Pós-Graduação em Educação (PPGEdu), Brasil. E-mail: kjc@terra.com.br.

3 Professora aposentada da Universidade Federal de Mato Grosso, campus de Rondonópolis, prestando serviço voluntário ao Programa de Pós-Graduação em Educação (PPGEdu). E-mail: nanci_barros@hotmail.com 


\begin{abstract}
We present data from a research that envisages to contribute to the reconstruction of the primary educational culture's memory, in the State of Mato Grosso, from the Cultural History and Educational Culture perspectives. We use the Reports from the Public Board of Education, elaborated by Major José Estevão Corrêa in the first five years that follow the Public Education Amendment, in 1910. Results indicate the power relations among educators from the State of São Paulo and educational authorities from the State of Mato Grosso, in the instauration of a new model of school, having as a consequence the construction of a differentiated educational culture from the one that has invigorated in the first decade of the $20^{\text {th }}$ century.
\end{abstract}

Keywords: primary school's memory; educational culture; educational groups.

\title{
Considerações iniciais: a pesquisa, suas fontes, sua metodologia
}

A pesquisa histórica em educação, com ênfase na Cultura Escolar, especialmente no que se refere ao ensino da leitura e escrita e seus suportes materiais, é hoje uma temática de importância nacional, cuja discussão começa a ganhar corpo em nível regional. Buscar a memória da cultura escolar é, de certa forma, buscar compreender e contribuir para a constituição de uma história das instituições educativas. A partir dessas reflexões desenvolvemos a pesquisa "Memória da cultura escolar mato-grossense: ensino primário, práticas de leitura e de escrita em grupos escolares, escolas reunidas e isoladas (1910-1970)", da qual apresentamos um pequeno recorte ${ }^{4}$. Buscamos respaldo em estudos da História Cultural, especificamente da Cultura Escolar, entendida como uma abordagem que possibilita estudos de temas, antes secundarizados. Pretendemos uma inserção nos meandros da história da escola primária mato-grossense na tentativa de circunscrever suas práticas, especialmente as relacionadas ao ensino de leitura e de escrita.

Como procedimentos metodológicos principais, a investigação recorreu à recuperação, reunião, seleção e organização de fontes documentais que continham referência ao ensino primário, especialmente ao ensino de leitura e de escrita nos grupos escolares e demais escolas da época. Para esta reflexão

4 Este texto, com modificações, foi apresentado no Congresso Luso Brasileiro de História da Educação, em 2010. 
elegemos a análise de um corpus de quatro relatórios de um diretor da Instrução Pública (entre 1910 e 1915). Enquanto versões discursivas produzidas por sujeito comprometido com seu tempo e com o pensamento hegemônico do grupo/classe a que pertenceu, essas fontes, em alguma medida, traduzem as representações e propósitos construídos pelos sujeitos da época.

Assim, temos como objetivos conhecer, compreender e sistematizar dados referentes à cultura escolar da escola primária em Mato Grosso, nos primeiros anos que se seguem à reforma da instrução pública realizada em 1910, tomando como referência os relatórios produzidos pelo inspetor da educação pública Major José Estevão Corrêa. Essa data constitui-se em um marco importante para a educação mato-grossense, pois nela ocorre uma reorganização do ensino, promovida por professores paulistas contratados pelo presidente Pedro Celestino, que almejava por uma reforma nos moldes republicanos, como a da reestruturação escolar no estado de São Paulo. A novidade daquele momento era a criação dos grupos escolares, já instituídos naquele estado em 1892 (SOUZA, 1998). Nos primeiros anos pós-reforma, a Diretoria da Instrução Pública de Mato Grosso teve a sua frente o Major José Estevão Corrêa, cuja trajetória nesse cargo aparece, alternadamente, desde os anos de 1897 até 1921, o que o torna uma figura emblemática para a pesquisa em questão, conforme quadro anexo.

Corrêa aparece no cenário educacional por longos anos. Comanda a Instrução Pública antes da reforma de 1910 e permanece no poder nos anos subsequentes, orquestrando um importante período de transição, cujo cenário seria palco da fundação de uma nova cultura escolar, marcada essencialmente pela escola graduada. De acordo com Frago, essa modalidade

implicava mudanças profundas na distribuição e usos do espaço e tempo escolares, na classificação e distribuição das crianças, na extensão e graduação e livros de texto, nos modos de avaliação e, em especial, na organização e gestão das escolas. Supunha uma nova cultura escolar e exigia uma mudança mental, uma mudança conceitual e de perspectiva que facilitasse a compreensão do que estava acontecendo e das possibilidades do novo sistema (FRAGO, 2005, p. 26).

Em Mato Grosso, como nos demais estados, vigoravam as escolas isoladas, em que o professor era responsável pela matrícula, pelo ensino, pelo aproveitamento dos alunos, pelo espaço físico da escola que, normalmente, era uma das dependências da casa do professor. Sem um currículo previamente definido, nem Plano de Aula, o período letivo e o horário das aulas ficavam 
também a seu critério ${ }^{5}$. A discrepância entre matrículas e frequência dos alunos gerava desconfiança das autoridades em relação à idoneidade dos professores ${ }^{6}$.

Situadas em uma tendência de renovação historiográfica no estudo da escola, do ensino e da educação e adotando uma perspectiva ampla em relação à noção e à utilização de documento, entendemos que os relatórios de José Estevão Corrêa são representativos dessa escola que vigorou no período imperial e grande parte do período republicano. Como testemunha desse período a trajetória desse sujeito que contribuiu com a construção da escola e da cultura escolar mato-grossense ganha importância. Suas queixas, seus receios, seus anseios e suas conquistas aparecem registrados nesse gênero textual, preservando parte da memória educacional deste estado.

\section{Os registros do Diretor José Estevão Corrêa}

\section{O legado da escola do passado}

A criação dos grupos escolares em Mato Grosso, entendida como "tradição inventada da escola primária no Brasil" (VIDAL, 2006, p. 9), foi forjada no cenário que a antecedeu, cuja organização administrativa e pedagógica fundava a cultura escolar dos oitocentos. A ideia de instituir os grupos escolares encontrou uma realidade material e cultural bastante adversa ao intento de disseminar um modelo de escola moderna, racional e orgânica.

Estudos anteriores (AMÂNCIO, 2008; REIS, 2003), evidenciam que a expansão dos grupos escolares não teve, em Mato Grosso, o mesmo destino de outros estados. Até o ano de 1930 foram instaladas apenas 11 unidades escolares nessa modalidade, para uma demanda de 8.726 alunos $^{7}$. Quanto à abrangência

5 Embora desde há muito se percebesse a fragilidade da escola do império, conforme pode-se observar no Decreto-Lei n. 7.247, de Leôncio de Carvalho, em 1879, que deu origem aos Pareceres de Rui Barbosa, a uniformização do ensino era um ideal a ser perseguido. Em 1877, o Ministro Lêoncio denunciava a precariedade das escolas, cada província determinava seu programa e sua legislação.

6 Temática semelhante é tratada por Vidal (2009, p. 34 s).

7 Segundo Mensagem do Presidente do Estado de Mato Grosso, Dr. Anibal Toledo, apresentada a Assembleia Legislativa e lida na abertura da $1^{\mathrm{a}}$ Sessão Ordinária de sua $15^{\mathrm{a}}$ Legislatura em Cuiabá, 13 de maio de 1930, havia, no ano de 1929, 175 Escolas Isoladas, 11 Grupos Escolares e 4 Escolas Reunidas, totalizando 190 escolas, para o atendimento a 8.726 alunos matriculados. Este relatório não menciona as escolas particulares e municipais. 
desses grupos escolares, vinte anos após a reforma (1930), estavam neles matriculados 3.391 alunos e, nas 175 escolas isoladas, estavam matriculados 5.334 alunos (AMÂNCIO, 2008, p. 105). Cabe análise e reflexão sobre a repercussão do ensino ministrado nos grupos escolares e nas outras modalidades de escola, inclusive nas escolas reunidas e nas escolas rurais.

Como legado histórico da cultura escolar oitocentista, podemos mencionar aspectos do "Estado da Instrução Pública" encontrados em um Relatório do Diretor Geral da Instrução Pública, José Estevão Corrêa, escrito em 1897 e endereçado ao Presidente do Estado. Corrêa lembra a última reforma implantada pelo Regulamento de 20 de junho de 1896, a qual previa a subordinação da Instrução Primária "aos processos intuitivos de Pestalozi, Froebel, Spencer e outros". Lembra, ainda, o Diretor que

De conformidade com o programa da reforma ficou instituído em primeiro lugar a Instrução Elementar obrigatória para todas as crianças de 7 a 10 anos de idade [...], depois a Instrução Complementar livre, [...] finalmente a Instrução Secundária tendo por fim especial, o preparo da mocidade com a cultura intelectual e moral, indispensáveis para o regular desempenho de qualquer profissão (CORRÊA, 1897).

Acreditava o Diretor que a execução desse plano de estudos traria a "regeneração do Ensino Público". No entanto, ponderava que muitas seriam, ainda, as dificuldades a serem superadas, já que

Preconceitos inveterados de um lado, costumes arraigados de outro, a pouca ilustração da maioria da população por uma parte e a má vontade de uns e o indiferentismo de muitos por outra parte, tais são os principais baluartes contra as quais terão de tecer armas no campo da luta, os operosos obreiros, a cujos cuidados está confiada a elevada missão de difundir o ensino obrigatório e intuitivo nas nossas Escolas de Ensino Elementar (CORRÊA, 1897).

Com lucidez o Diretor se pergunta e, ao mesmo tempo, responde: "Mas, a reforma, nos termos em que foi decretada, satisfará acaso todas as exigências da época ou todas as aspirações da atualidade? Longe disso". Seus argumentos defendem a ideia de "que a Instrução Elementar deve ser mantida, não pelos 
cofres estaduais, mas a expensa dos Municípios, ficando reservado para o Estado, somente a Complementar e a Secundária".

Entendendo que "O Magistério Primário do Estado, não está ainda convenientemente preparado para o bom desempenho das importantes funções que lhe são cometidas no recente Regulamento Orgânico", o Diretor relata que expediu uma circular aos professores da capital, orientando-os, entre outras coisas, em relação à necessária adoção de obras didáticas "para lecionarem com proveito e bem encaminharem a frágil inteligência das crianças":

Ao vosso critério cabe certamente fazer a escolha dos livros [...] Entretanto, lembrar-vos-hei que, além de outros [...], também muito se recomendam como sendo própria para conseguimento de tal desinderatum, as seguintes obras didáticas que se acham à venda na Casa Editora de Alves e Campos da Capital Federal: Noções da Vida Prática e Noções da Vida Doméstica, por Félix Ferreira; Pátria e Dever e $\mathrm{Na}$ terra, no mar e no espaço, por Hilário Ribeiro e Lições de cousas, por Zaluar. Além destas obras, há igualmente a excelente Revista Pedagógica, denominada Escola Pública, [...] da qual não poderá prescindir jamais o professor que bem deseje cumprir na escola, os árduos deveres de sua nobre e penosa profissão (CORRÊA, 1897).

Em relação aos métodos de ensino, Corrêa defende a sua adequação à disciplina, ao nível das classes e ao número de discípulos, apontando para a sua variedade:

Os métodos de ensino variam naturalmente, quer em relação à disciplina que faz objeto do ensino, quer enquanto ao grau de adiantamento ou atraso das classes escolares como ainda com respeito ao número de discípulos a lecionar em cada classe. [...] Atendendo a esta importante consideração, prescrevi no Regimento Interno das Escolas, que se refere aos métodos, modos, formas e processos do ensino, que os Professores se guiassem pelo que se acha compreendido a respeito no Tratado de Metodologia do Professor Felisberto de Carvalho, que é o que eu conheço de melhor em semelhante especialidade (CORRÊA, 1897).

Em relação aos edifícios escolares, Corrêa defende a necessidade premente de o Estado dotar a educação de edifícios próprios para as escolas públicas. Relata 
que, excetuando três escolas da capital, uma da Vila de Rosário, uma da Vila de Diamantino, uma da Vila de Capão do Pequi e uma da cidade de Corumbá,

todas as mais funcionam em casas particulares, cujos aluguéis são pagos pelos respectivos Professores, auxiliados nesta parte com uma módica subvenção que mensalmente recebem dos Cofres Estaduais. Mas, nem os próprios edifícios públicos, nem muito menos os particulares a que me refiro, nenhum deles se presta aos fins a que se destinam [...] (CORRÊA, 1897).

O Diretor salienta, ainda, que a distribuição dos utensílios destinados para os exercícios escolares dos meninos indigentes matriculados nas Escolas Públicas da Instrução Primária "sempre foi má e defeituosa e continua sem a regularidade necessária”. Explica que

Causas complexas concorrem para isso, sendo uma delas a dificuldade das remessas para as Escolas longínquas, e outro fato de não se conhecer, nem sequer aproximadamente, o número de meninos indigentes que freqüentam as escolas do interior e estão por conseguinte nas condições de gozar do favor que a lei lhes concede (CORRÊA, 1897).

Corrêa atribui esse desconhecimento ao descumprimento de dever dos Inspetores Escolares, inscrito no Regulamento de 1896, pois é certo que esses

têm o dever de remeter semestralmente à esta repartição a relação nominal dos alunos pensionistas matriculados nas escolas sob sua jurisdição, mas não é menos certa que nenhum deles cumpre com semelhante dever de modo que só imperfeitamente e com certa injustiça relativa, terão de continuar ainda a ser feitos os suprimentos de tais artigos para as escolas do interior (CORRÊA, 1897).

A voz de Corrêa, uma das últimas a ecoarem no limiar do século XX, não é a única e nem a primeira a denunciar as precariedades da escola mato-grossense no final do século XIX. Entre outras, juntam-se a ela, décadas antes, 
as lamentações de Camilo Barreto (1870) em seu substancioso e circunstanciado relatório da Instrução Pública. A implantação de um novo modelo administrativo e pedagógico estava impregnada de muitas expectativas, encontrando, no entanto, inúmeras adversidades na instituição de uma cultura escolar diferenciada da que representava as escolas da época, como veremos a seguir.

\section{A constituição da escola republicana}

Trataremos nesse item da trajetória da escola republicana em Mato Grosso no primeiro quinquênio pós-reforma 1910, segundo Relatórios de José Estevão Corrêa. Seguem algumas "cenas" mediante as quais se pode observar aspectos do esforço e da esperança de construção de uma (nova) realidade escolar, mais adequada aos novos tempos da educação mato-grossense.

\section{Primeira cena: 1910}

Grandes eram as esperanças no início da década de 1910. Treze anos depois do relatório de 1897, Corrêa, ainda no mesmo cargo, acreditava que a reorganização libertara a instrução pública do "estado doentio em que [esta] se debatia sob o poder da velha rotina que tanto atrofiava o seu desenvolvimento". O Diretor da Instrução Pública, entusiasmado com a (re)criação da Escola Normal e da implantação da Escola graduada, ambas pautadas nos "princípios e regras da pedagogia moderna", assim se manifestou em relatório de 1910:

acredito não haver temeridade em lhe assegurar para breve a época de seu florescimento, desde que sejam como cuido que hão de ser, as novas escolas servidas por professores convenientemente preparados [...] de modo a baterem com segurança os imprevistos caminhos do futuro, certos de serem um dia vencedores nas justas aspirações de suas legítimas esperanças (CORRÊA, 1911).

Quando viria o futuro auspicioso sonhado por Corrêa? Ele próprio, em março de 1911, referindo-se ao ano anterior, ainda ocupando o lugar de Diretor 
da Instrução pública, registrou: até que "este vaticínio se transforme em realidade longo estádio haverá ainda a percorrer, muito trabalho a executar e grandes dificuldades a superar". Sua descrença era em relação à situação do professorado que, para ele, não tinha idoneidade para o seu trabalho e aos processos de ensino "gastos e anacrônicos", desenvolvidos em "escolas atrasadas". O pouco tempo decorrido após a reforma, certamente, não permitia, ainda, grandes alterações. Além disso, estudos evidenciam que a implantação da escola graduada em outros locais, como na Espanha (FRAGO, 2005) se deu lentamente, tendo como uma das explicações

a resistência de boa parte dos professores a integrar-se em um modelo de organização escolar em que, diferentemente das escolas não-graduadas deviam coordenar sua tarefa com outros companheiros e submeter-se ao controle imediato e direto do diretor frente ao controle distante do inspetor (FRAGO, 2005, p. 26).

Esse autor menciona, ainda, que os problemas mais importantes nesse novo modelo não eram somente de índole financeira ou política, mas, também, de ordem mental e organizativa. Apesar da aparente descrença, o Diretor registra números referentes à matrícula de alunos, evidenciando um aumento no total de 2.707 para 3.326 (Relatórios dos anos de 1911 e 1912). Ainda nesses relatórios, Corrêa informa que das 79 escolas, 5 não enviaram seus mapas mensais e 19 delas deixaram de funcionar, provavelmente em função da organização dos dois grupos escolares da capital, cujas turmas foram constituídas com alunos de diferentes escolas. Os números referentes aos grupos escolares também não fazem parte dessa estatística.

Não sem razão, Corrêa preocupava-se, constantemente, com os materiais escolares, pois "no processo de renovação da escola primária no século $\mathrm{XX}$, esses materiais fizeram parte das grandes questões tematizadas acerca da organização pedagógica do ensino" (SOUZA, 1998, p. 223). Desse modo, em relação aos "utensílios ${ }^{8}$ destinados aos meninos indigentes", o Diretor informa que, embora tenham sido encomendados com antecedência ao Rio de Janeiro, "não puderam eles chegar com tempo a esta Capital, de modo a serem conve-

8 Estamos, aqui, entendendo a palavra "utensílios" numa acepção ampla que engloba todos o materiais considerados "indispensáveis para o regular funcionamento" das escolas, tais como, objetos (potes para água, escarradeiras, relógio), materiais de consumo (querosene, goma arábica, tinta) e materiais didáticos (livros e cadernos), visto que nos relatórios não se encontra distinção entre essas categorias. 
nientemente distribuídos às mesmas escolas nos dois semestres do ano próximo passado", reproduzindo, assim, uma situação já mencionada no final do século XIX (CORRÊA, 1911).

No que se refere ao mobiliário escolar, Corrêa menciona que, em 1909, obteve permissão para efetuar uma compra, mandando vir de "Nova York, por intermédio do representante da "American Leating Company Brasil", quatrocentas carteiras com assento duplo e [...] bancos para a renovação do velho e imprestável mobiliário das escolas do Estado" (CORRÊA, 1911). A maior parte desse rico material, aqui chegado no final do ano de 1910, foi destinada às escolas da capital, contemplando, ainda, algumas de Corumbá. Já os bancos, segundo o relato, ficaram na repartição, pois eram destinados à educação infantil, anexa à escola Normal, que, segundo o Diretor, não fora ainda instalada. Na realidade poucas são as notícias do funcionamento do Jardim de Infância9 , criado no Regulamento de 1910.

O tema edificios escolares é mencionado, ainda, pelo Diretor, que salienta os esforços do Presidente do estado em dotar os "institutos de ensino com casas apropriadas no tríplice ponto de vista da comodidade, da higiene e da educação física dos alunos", mas que "embaraços imprevistos" retardaram tal intento. Manifesta, ainda, sua crença na realização desse objetivo pelo próximo presidente.

Muitos outros aspectos de ordem administrativa são abordados nesse Relatório, excluindo-se, no entanto, questões pedagógicas, tais como métodos aplicados e materiais didáticos distribuídos. O Diretor termina o relatório lamentando não poder prestar contas sobre o funcionamento das "escolas do interior relativamente à educação física, intelectual e moral dos respectivos alunos, cujo grau de aproveitamento ou atraso é assim absolutamente desconhecido das autoridades superiores do ensino nesta Capital" (CORRÊA, 1911). Em mais uma recorrência de reclamação, tal desconhecimento é creditado à "obstinação ou indiferentismo dos Inspetores Escolares" ${ }^{10}$ que se negam a investigar nas escolas os aspectos mencionados, configurando-se seu desempenho como uma inspeção inadequada ao novo sistema de ensino. Esse é um tema do qual a educação em Mato Grosso não vai se livrar nas próximas décadas.

9 Entre as esparsas notícias sobre a educação da infância, na primeira metade do século XX, encontramos uma nota no Jornal $A$ Cruz anunciando matrículas abertas para o Jardim de Infância no Asylo Santa Rita, em Cuiabá, no ano de 1939.

10 O cargo de inspetor escolar era indicado pelo poder público, não cabendo-lhe remuneração, até a criação, em 1921, da Inspetoria Geral do Ensino (remunerada) (LEITE, 1970). 


\section{Segunda cena: 1911}

A permanência do Diretor Corrêa no cargo é testemunhada por seu próximo relatório, referente ao ano de 1911, datado de 29 de março de 1912. Nesse Relatório, o item da Instrução Primária se inicia com um entusiasmado discurso republicano:

A educação e instrução populares constituem nos dias atuais o supremo ideal das sociedades modernas que acompanhando de perto o movimento evolutivo da época, envidam o melhor de seus esforços no empenho de aperfeiçoar, de cada vez e mais, a organização de seus institutos de ensino, quer melhorando quantitativamente os aparelhos pedagógicos de suas escolas, quer escolhendo com meticuloso cuidado os mestres e professores que se incumbem de sua direção e regência. Negar a influência social da educação, o mesmo seria que negar as próprias leis do progresso e da civilização dos povos cuja grandeza decorre do grau da cultura de cada um deles e constitui por assim dizer, o granito sobre que se alicerça o edifício de sua felicidade coletiva. Não se estranhe pois, que neste contínuo peregrinar pela infinita estrada da civilização, também Mato Grosso procura desferir os seus vôos de ensaio em busca de perfectibilidade com que sonha para assegurar-lhe uma posição de destaque nos domínios da cultura moral e intelectual de seus habitantes. (CORRÊA, 1912).

Em que pese a busca pela perfeição de uma escola representativa "do progresso e da civilização", continuam a sobressair nesse relato as adversidades próprias de um momento de um "ciclo de hibridação" (VIDAL, 2009, p. 30) entre a escola do passado e a escola moderna. É assim que encontramos Corrêa apontando que, embora o Regulamento da Instrução Pública tenha sido forjado nos moldes de processos didáticos mais avançados, "não se pode com justiça contestar que em seus principais lineamentos, esteja aquele regulamento de perfeito acordo com o costume popular que não é possível aniquilar-se de momento, nem facilmente derrubar-se". Nota-se aqui uma reflexão do diretor no que concerne à dificuldade de ruptura de uma tradição e consequente construção de uma nova cultura escolar.

Outro motivo de descontentamento por parte do Diretor era o regime disciplinar imposto aos alunos dos grupos escolares, herdado da "antiga" cultura escolar. Para ele, 
Não, não é disciplina essa que faz as crianças se moverem como polichinelos ao som de um tímpano anacrônico pois que a ordem se obtém sem necessidade desses processos grotescos, incompatíveis com a educação afetiva sobre a qual deve assentar-se toda a boa disciplina de uma escola. Não é disciplina essa que quer a criança imóvel de braços cruzados, em atitude servil, a ouvir uma lição. [...] Nada disso, fazemos questão da disciplina que educa o aluno na escola do dever ensinando-o a fazer bom uso de sua liberdade, de modo a não desmerecer jamais do bom conceito, nem por parte de seus preceptores, nem pela de qualquer de seus colegas (CORREAA, 1912).

Outros aspectos, ainda, preocupavam o Diretor da Instrução Pública. Um deles se referia ao fato de que o Decreto de 20 de agosto, que instituiu os grupos escolares da Capital, previa que esses se regessem "provisoriamente e no que lhes fosse aplicável", pelo regulamento e programa dos Grupos Escolares do Estado de São Paulo". No entanto, "Aquele provisório, porém, continua como que permanente em razão de não haver sido até hoje regulamentado o serviço dos mesmos grupos" (CORRÊA, 1912).

Mas há, ainda, mais preocupações e dissabores, como: "o fato de não haver recebido o relatório dos serviços desempenhados no ano último pelo grupo do $1^{\mathrm{o}}$ distrito, e pouco adiantou naquele sentido o do $2^{\circ}$ distrito que ofereço a este anexo [...]" (CORREAA, 1912). Embora esse Relatório contemple, ainda, a mesma reclamação do ano anterior, relacionada à fiscalização do ensino, o Diretor aponta a profunda transformação administrativa que ocorre nos grupos escolares:

Do ponto de vista da fiscalização, é incontestável a superioridade de que se dá nossos grupos escolares comparado com as escolas avulsas. Os grupos são verdadeiras repartições públicas onde diretores e professores mutuamente se fiscalizam, tendo por isso neles dispensada a presença constante das autoridades encarregadas de sua inspeção (CORRÊA, 1912).

\section{Terceira Cena: 1912}

No relatório divulgado em 1913, Corrêa informa a existência de 5 grupos escolares $^{11}$ e 96 escolas avulsas, sendo que destes, apenas 16 tinham prédio

11 Foram seis os grupos escolares criados pelos decretos n 258 de 20 de agosto de 1910 e $n^{\circ} 297$ de 17 de janeiro de 1912, mas o de Corumbá ainda não estava em funcionamento. 
próprio. Relata que, entre salários de professores, aluguéis de casa, material escolar e de expediente e asseio gastou-se 323:915\$734 réis, correspondente a décima parte da renda estadual. Argumenta que "existem nesses estabelecimentos 3.475 alunos matriculados com freqüência média de 2.789 , o que dá para cada um dos matriculados a despesa anual de $93 \$ 200$ réis e para cada freqüente a de $116 \$ 140$ réis" (CORRÊA, 1913). Para evidenciar que esses gastos não eram absurdos, Corrêa apresentou um quadro de despesas parciais com o ensino primário de todos os estados e do distrito federal, mostrando como Mato Grosso ocupava o segundo lugar com a menor aplicação $(6,7 \%$ da receita, ficando à frente apenas de Pernambuco (4,5\% da receita) e muito distante do Distrito federal (28,03\% da receita).

Esse relatório fornece, ainda, números das matrículas e frequências nos grupos escolares e, mais adiante, a estatística das 92 escolas isoladas espalhadas pelo estado. Os dados dos grupos mostram 1.041 matrículas e 817 alunos frequentes. Já as escolas avulsas somam 2.435 matrículas e 1998 alunos frequentes.

Em relação à fiscalização, aponta-se incongruências entre as novas normatizações e a realidade. Dependendo de um acordo com governos municipais, o serviço de fiscalização feito por um "elemento local como o único meio capaz de normalizá-lo principalmente nas escolas do interior" ainda não vigorara. Com a fiscalização entregue às autoridades da capital, o serviço dos inspetores se resumia

ao trabalho de assinarem atestados mensais de assiduidade dos professores, e isso mesmo quando não se eximem também do cumprimento deste fácil dever para deixarem entregues as autoridades municipais ou policiais de cada distrito, como a miúdo sucede (CORRÊA, 1913).

A fiscalização das escolas configurou-se, ao longo do tempo, como uma das maiores dificuldades do sistema escolar, desafio que acompanhou por mais de um século o desenvolvimento da instrução pública. Considerando o início das escolas de primeiras letras a partir do Subsídio Literário - 1772 - e a implantação dos grupos escolares - 1910 -, vemos que o sistema dos grupos era extraordinariamente superior ao que ocorria com as escolas isoladas que dependiam da fiscalização dos inspetores de ensino ${ }^{12}$.

12 Em 1943 o relatório do Inspetor Eusediades Gomes apresenta resultados dos exames orais dos alunos das escolas isoladas da região de Campo Grande, sul do estado. Em 1952, o inspetor José Bruno Santana Neto, denuncia as condições das escolas rurais no município de Guiratinga. Revelam, essas fontes, que a questão da fiscalização do ensino permanecia um problema ainda em meados do século XX. 
Este problema, no entanto, dizia respeito apenas às escolas do interior, e não aos grupos escolares, já que estes

não só estão passando ainda por sua fase de organização, como por constituírem verdadeiras repartições públicas, cujos serventuários se fiscalizam mutuamente, quer enquanto a freqüência e correção de conduta de cada, como no que se refere a orientação pedagógica de seu pessoal docente (CORRÊA, 1913).

Referindo-se ao mobiliário, Corrêa relembra a compra do ano anterior feita nos Estados Unidos da América, salientando sua insuficiência. Desse modo, impõe-se

a necessidade de mais bancos-carteiras, mesas, armários, relógios, quadros negros em telas ardosiadas, não só para o fornecimento da maior parte das escolas do interior, como para a substituição do mobiliário já arruinados em muitas delas (CORRÊA, 1913).

Em sua conclusão, o Diretor da Instrução Pública é enfático em relação às muitas reclamações já sinalizadas anteriormente, mostrando-se seguro para apresentar quaisquer detalhes ou explicações, relativamente a assuntos referentes às escolas.

Esse Relatório evidencia que dois anos pós-reforma, o número de grupos escolares era ainda diminuto, permanecendo a educação dos mato-grossenses distanciada da racionalidade prevista para os imponentes grupos escolares. A ação modernizadora do governo republicano permanecia à espera de concretização.

\section{Quarta cena: $1915^{13}$}

O Relatório de 1915, publicado em 1916, encerra o corpus aqui trabalhado. Esse relatório tem seu início marcado pelo posicionamento de Corrêa, que invoca a atenção de seu interlocutor 
para o estado de nossa instrução oficial, que, no meu modo de pensar, precisa ser reorganizada, não pelo vezo de reformar o que está feito como a alguns possa por ventura parecer, mas, entre outras considerações, também para acompanhar, ainda que de longe, a evolução progressiva do ensino nos centros mais adiantados, e estabelecer ao mesmo tempo o equilíbrio e harmonia de conjunto que não existem nas variadas disposições pelas quais se rege aquele importante ramo da administração estadual (CORRÊA, 1916).

A grande queixa do Diretor é em relação às antinomias inerentes ao regulamento geral de 1910 e a incapacidade da comissão especial eleita para elaborar um (novo) regulamento para os grupos escolares. Queixa-se, ainda, das "divergências dos regulamentos parciais no modo de imporem preceitos e regras diferentes para soluções de casos análogos e até idênticos como são os de concursos, exames, matrículas, licenças, substituições e outras" (CORRÊA, 1916).

Após marcar discursivamente seu posicionamento político, o Diretor dedica-se a apresentar dados da Instrução Pública. É apontada a existência de 144 escolas primárias no Estado, sendo que 18 delas estão incorporadas aos grupos e as 126 restantes constituem as escolas avulsas ou isoladas.

Corrêa aborda a questão do ensino obrigatório, ponderando que, se o ensino primário tem apologistas convictos e alguns até fanáticos, também conta com oposicionistas sinceros, e muito obstinados" (CORRÊA, 1916). O Diretor apresenta argumentos relacionados às duas posições, enfatizando, de um lado, o direito do estado de obrigar pais, tutores e outros responsáveis por crianças a irem à escola para aprender a ler e a escrever e, por outro lado, a impossibilidade de adoção do ensino obrigatório, devido à falta de um recenseamento escolar e, ainda, que este fere de frente a liberdade individual do cidadão. Nesse sentido, Corrêa acaba por defender a supressão desse princípio no Regulamento Geral da Instrução Pública:

Nestas condições, parece razoável que, em alguma reforma e que futuro se haja de proceder neste mesmo serviço estadual, se apague do corpo de sua legislação escolar, uma semelhante medida, que por ineficaz em seus efeitos não convém que nela continue a figurar como tem até agora figurado (CORRÊA, 1916). 
Dado que a questão da obrigatoriedade da escolarização já estava cogitada desde o século XIX ${ }^{14}$, constituindo-se num avanço democrático que atendia ao ideal republicano, a atitude do diretor parece mais um retrocesso vinculado às dificuldades de implementação de uma educação pensada, desejada, mas de difícil realização.

Esse parecia ser mais um condicionante à construção de uma nova cultura que requeria a adoção de novos materiais, de infraestrutura, de novo referencial na formação dos professores, organização de novos tempos e espaços; e, sobretudo, uma nova mentalidade (FRAGO, 2005), associada a um grau elevado de autonomia dos professores.

\section{Considerações finais: entre o desejável e o possível}

Essas fontes documentais evidenciam a permanência de uma cultura escolar, constituída ao longo da história da instrução pública brasileira, cuja realidade resistia bravamente às profundas e necessárias alterações preconizadas pela escola moderna.

Da análise dos relatórios do Major José Estevão Corrêa, ainda que correspondente a apenas cinco anos, é possível supor que o desejo de uma escola moderna, mais adequada ao novo ideário divulgado pelos republicanos estava produzindo, mesmo que lentamente, uma nova concepção de escola. Todavia, o ritmo das alterações no (micro)contexto escolar, que, obviamente, acompanhava o ritmo dos movimentos socioeconômicos e políticos regionais, parece não ter contribuído para dar visibilidade à constituição de uma nova cultura escolar. De acordo com Reis Filho (1995), estudioso da reforma da educação paulista, as inovações educacionais, no Brasil, não se expandiram homogeneamente, dadas as diferenças econômicas regionais. Explicar-se-ia, assim, o fato de regiões como o estado de São Paulo, em que a acumulação de capital se iniciava, ter adotado essas inovações mais cedo, por receber, aos poucos, suporte socioeconômico para sua concretização.

Em que pese a análise aqui realizada das "cenas" visualizadas por meio dos registros de Corrêa, em torno e além da escola há um movimento efervescente

14 Acompanhando a legislação nacional, os regulamentos da instrução pública de Mato Grosso, dos anos de 1880, 1891, 1896, 1910, apenas para citar alguns que antecedem e um que entra no período republicano, tratam entre vários itens da questão da obrigatoriedade do ensino e penalidades aplicadas aos pais que ignoravam a legislação. 
constituído por ações de outros sujeitos, seus contemporâneos. Desse modo, pode-se refletir: até que ponto a criação de alguns grupos escolares, a discussão de novas metodologias, a divulgação de conferências dos normalistas paulistas na imprensa cuiabana, o trabalho do Conselho Superior da Instrução Pública (AMÂNCIO, 2008), a presença de novos materiais didáticos e utensílios, a criação da Biblioteca Pública entre outras iniciativas, influenciaram, ainda que de forma incipiente, a constituição de novas representações sobre a escola primária?

No entanto, para explicar a morosidade, vale lembrar que a Escola Normal, em funcionamento apenas desde 1911, vinha formando professores para trabalharem nos grupos escolares. O número de formados pela Escola Normal ficou muito aquém da demanda (AMÂNCIO, 2008, p. 118-119), desde a colação de grau da primeira turma, em 1913, com seis normalistas e da segunda, em 1915, com nove. Como construir uma nova cultura apenas com uma legislação, que impõe "boas" prescrições? Onde os professores especializados? Onde os prédios adequados? Onde a fiscalização necessária?

O mais visível, nesse processo, parecia ser a força das adversidades, mantendo a precariedade e impedindo o florescimento de uma escola minimamente preparada para atender todas as crianças mato-grossenses, especialmente na primeira metade do século XX.

A enorme distância entre a proposta da escola graduada e as ações efetivadas no sentido de mudar a escola primária em Mato Grosso pode ser responsabilizada pela permanência de uma cultura escolar que sofreu poucas alterações ao longo século XX. Esses aspectos da cultura escolar nos levam a concordar com Vidal (2009), no que concerne a pensar numa "hibridação" cultural, considerando a permanência de elementos do legado do passado associados à nova modalidade escolar.

Por fim, tendo José Estevão Corrêa assumido novamente o cargo de Diretor da Instrução Pública, no ano de 1920, aborda em Relatório a existência dos mesmos grupos escolares, lamentando: "Infelizmente encontram-se esses estabelecimentos de ensino muito longe do fim para que foram criados, exceção feita ao Grupo Escolar Modelo, que tem mantido até hoje a sua matrícula sempre crescente" (CORRÊA, 1921). A escola republicana tinha, em Mato Grosso, um longo caminho a trilhar.

\section{REFERÊNCIAS}

AMÂNCIO, Lázara Nanci de Barros. Ensino de leitura e grupos escolares em Mato Grosso: 1910-1930. Cuiabá: EdUFMT, 2008. 
BRASIL. Decreto n. 7.247, de 19 de abril de 1879. Reforma do Ensino Primario, secundário e superior no Município da Corte em todo o Império. In: BARBOSA, Rui. Reforma do ensino secundário e superior. Obras Completas. Rio de Janeiro: Ministério da Educação e Saude, 1942. Tomo I, v. IX, p. 273-303.

BRASIL. Ministério do Império. Ministro Carlos Leôncio de Carvalho. Relatório do ano 1877, apresentado na $1^{\mathrm{a}}$. Sessão da $17^{\mathrm{a}}$. Legislatura. Rio de Janeiro: Typ. Nacional, 1878.

FRAGO, Antônio Viñao. Espaços, usos e funções: a localização e disposição física da direção escolar na escola graduada. In: BENCOSTA, Marcus Levy Albino (Org.). História da Educação, arquitetura e espaço escolar. São Paulo: Cortez, 2005. p. 15-47.

JORNAL A CRUZ. n. 1375, anno XXIX.Cuiabá, 12 fev. 1939.

LEITE, Gervásio. Um século de instrução pública: história do ensino primário em Mato Grosso. Goiânia: Goiás, Ed. Rio Bonito, 1970.

MATO GROSSO. Relatório do Diretor Geral da Instrução Pública, José Estevão Corrêa, ao Sr. Dr. Antônio Corrêa da Costa, Presidente do Estado de Mato Grosso no ano de 1896.

. Relatório do Diretor Geral da Instrução Pública, Sr. José Estevão Corrêa, ao Presidente do Estado, Coronel Pedro Celestino Corrêa da Costa. Cuiabá, 1911.

. Relatório do Diretor Geral da Instrução Pública, Sr. José Estevão Corrêa, ao Presidente do Estado, Joaquim Augusto da Costa Marques. Cuiabá, 1912.

. Relatório do Diretor Geral da Instrução Pública, Sr. José Estevão Corrêa, ao Presidente do Estado, Joaquim Augusto da Costa Marques. Cuiabá, 1913.

. Relatório do Diretor Geral da Instrução Pública, Sr. José Estevão Corrêa, ao Presidente do Estado, Caetano M. de Faria e Albuquerque. Cuiabá, 1916.

. Relatório do Diretor Geral da Intrução Pública, Sr. José Estevão Corrêa, ao Presidente do Estado, D. Francisco de Aquino Corrêa. Diretoria Geral da Instrução Pública. Cuiabá, 1921.

. Oficio n. 04, do Inspetor José Bruno Santana Neto encaminhado em 03 de maio de 1952 ao Diretor do Departamento de Educação e Cultura, Francisco Ferreira Mendes. Documento avulso. 1952 - caixa A. APMT.

REIS, Rosinete Maria. Palácios da Instrução: institucionalização dos grupos escolares em Mato Grosso (1910-1927). Dissertação (Mestrado em Educação) - Programa de Pós-Graduação do Instituto de Educação, UFMT, Cuiabá, 2003.

REIS FILHO, Casemiro. A educação e a ilusão liberal: origens da escola pública paulist. Campinas: Autores Associados, 1995.

SOUZA, Rosa Fátima de. Templos de civilização: a implantação da Escola Primária Graduada no estado de São Paulo (1890-1910). São Paulo: UNESP, 1998.

VIDAL, Diana (Org.). Grupos Escolares: cultura escolar primária e escolarização da 
infância (1893-1971). Campinas: Mercado de Letras, 2006.

. No interior da sala de aula: ensaio sobre cultura e prática escolares. Currículo sem Fronteiras, v. 9, n. 1, p. 25-41, jan./jun. 2009. Disponível em: <http://www. curriculosemfronteiras.org $>$. Acesso em: 20/5/2010.

\section{ANEXO}

QUADRO 1 - RELAÇÃO DE DIRETORES DA INSTRUÇÃO PÚBLICA - 1897-1921

\begin{tabular}{|l|l|l|}
\hline ANO & $\begin{array}{c}\text { DIRETORES DA } \\
\text { INSTRUÇÃO PÚBLICA }\end{array}$ & GOVERNANTES DO ESTADO \\
\hline 1897 & José Estevão Corrêa & Sr. Dr. Antônio Corrêa da Costa \\
\hline 1898 & José Estevão Corrêa & Antônio Corrêa da Costa \\
\hline 1899 & Joaquim Silva Rondon & Sr. Coronel Antônio Pedro Alves de Barros \\
\hline 1902 & Januário da Silva Rondon & Antônio Alves de Barros \\
\hline 1905 & Januário da Silva Rondon & Sr. Cel. Antônio Paes de Barros \\
\hline 1907 & José Estevão Corrêa & Pedro Leite Osório \\
\hline 1908 & José Estevão Corrêa & Sr. Coronel Paes Leme de Souza Ponce \\
\hline 1909 & José Estevão Corrêa & Pedro Celestino Corrêa da Costa \\
\hline 1911 & José Estevão Corrêa & Pedro Celestino Corrêa da Costa \\
\hline 1912 & José Estevão Corrêa & Joaquim Augusto da Costa Marques \\
\hline 1913 & José Estevão Corrêa & Joaquim Augusto da Costa Marques \\
\hline 1916 & José Estevão Corrêa & Caetano Manoel de Faria e Albuquerque \\
\hline 1917 & Dr. Cesário Alves Corrêa & Caetano Manoel de Faria e Albuquerque \\
\hline 1921 & José Estevão Corrêa & Dom Francisco de Aquino Corrêa \\
\hline
\end{tabular}

FONTE: Quadro elaborado a partir dos Relatórios da Instrução Pública, catalogados no APMT.

Texto recebido em 08 de setembro de 2012.

Texto aprovado em 29 de setembro de 2012. 
